\title{
Information Technology-Infused Physical Ground Management
}

\author{
Xi-ying ZUO \\ Department of P. E., Henan University of TCM \\ Zhengzhou 450046 \\ Henan, China
}

ABSTRACT: Currently there are many technological developments in the design and construction of sports grounds. One such growth is the use of computational intelligence for design and construction. From the venue selection till the completion, the use of intelligent techniques is visible and the system can able to help the information exchange. The computer control system helps for the design and placement of equipment. The present work will study the information resource, equipment use, energy saving system and the energy efficient system formulation.

Keywords: Information Technology in Sports, Computer assisted System Design, Intelligence in Sports Management, Intelligence in Sports Management

Received: 22 February 2019, Revised 19 May 2019, Accepted 26 May 2019

DOI: $10.6025 / \mathrm{jic} / 2019 / 10 / 3 / 91-96$

\section{(C) 2019 DLINE. All Rights Reserved}

\section{Introduction}

With the flourishing development of the sports career and the success of the Olympic Games in Beijing, in 2008, different kinds of stadium have been built increasingly all over the nation, becoming the main venue of recreation for people. However, during the process of construction of some specialized stadium, the extent of intelligence has reduces due to various reasons, thus affecting people's demand for intelligent buildings. Therefore, according to the need of stadium construction, the national construction industry, begin to stipulate the relevant standards in the area of intelligent construction combined with the latest development of information \$ technology, thus providing technical guide for the intelligent construction and design of stadium, perfecting and optimizing intelligent system and realizing the intelligent design of stadium.

\section{The Characteristics of Stadium}

Due to the multiple functions and the great number of speculators, the cover of area is usually big, approximately ranging from $200000 \mathrm{~m}$ to $1100000 \mathrm{HI}$ in most of the case. A small portion of the area of stadiums is shown in Table 1. 


\begin{tabular}{|l|c|c|}
\hline Stadium & Covering area & Building area \\
\hline Shanghai Stadium & 18 & 17 \\
\hline Guangzhou New Stadium & 24 & 10 \\
\hline Nanjing Olympic centre & 40 & 29.5 \\
\hline Suzhou sports centre & 21 & 11.4 \\
\hline
\end{tabular}

Table 1. Part of the summery of the covering area of stadium in China

\subsection{The General Investment is Huge}

Due to the large area, the demand for capital investment is huge in the process of construction. For the relatively small stadium, hundreds of millions should be invested; for the relatively large stadium, almost one billion is needed. During the process of intelligent construction, the expenditure on the construction of intelligent system consists of $4 \% \sim 5 \%$ of the investment in the whole construction. Moreover, the daily expenditure is also considerable.

\begin{tabular}{|l|c|c|}
\hline Stadium & Total investment (hundred million, RMB) & Operational cost(RMB/hour) \\
\hline Shanghai Stadium & 13 & 3150 \\
\hline Guangzhou New Stadium & 12 & 5682 \\
\hline Nanjing Olympic centre & 22.2 & 13860 \\
\hline Suzhou sports centre & 7 & 5040 \\
\hline
\end{tabular}

Table 2. Stadium investment and operational cost

\subsection{A Large Flow of Crowd}

In the case of competition or performance in stadium, the large flow of crowd and the busy traffic have placed the potential risk to safety. So a more comprehensive video surveillance system is highly needed to control the situation around and therefore, the issues can be found timely and be dealt with on the spot. Then the security of the speculators and stadium are guaranteed.

\section{The Conception of Intelligent Stadium System}

Intelligent buildings, according to the standards in China, can be defined: "it is a set of facilities with the characteristics of safety, comfort and convenience, including various kinds of electrical equipment, office environment and communication system via optimizing construction structure, system management and service quality". The stadium intelligent system, which also has the function of warmness and ventilation, is a part of intelligent buildings. Moreover, it also possesses the necessary equipment of construction structure and electrical equipment. Intelligent design can provide venue and other services for athletic training and competition, including information services, network communications services and presentation services, etc.

\section{The Current Situation of Intelligent Stadium System}

\subsection{The Current Situation of Intelligent Stadium System in Abroad}

In abroad, the conception of intelligent construction has already been applied in the whole life circle of intelligent buildings. Especially, the functioning systems, in the early and mid-stage operation, are able to have a better effect on saving energy by optimizing design, enhancing controllability and exploiting the potential of original products and design fully. In contrast with European countries, the conception of intelligent construction in China is relatively narrow, thus being likely to limit our mindset. 


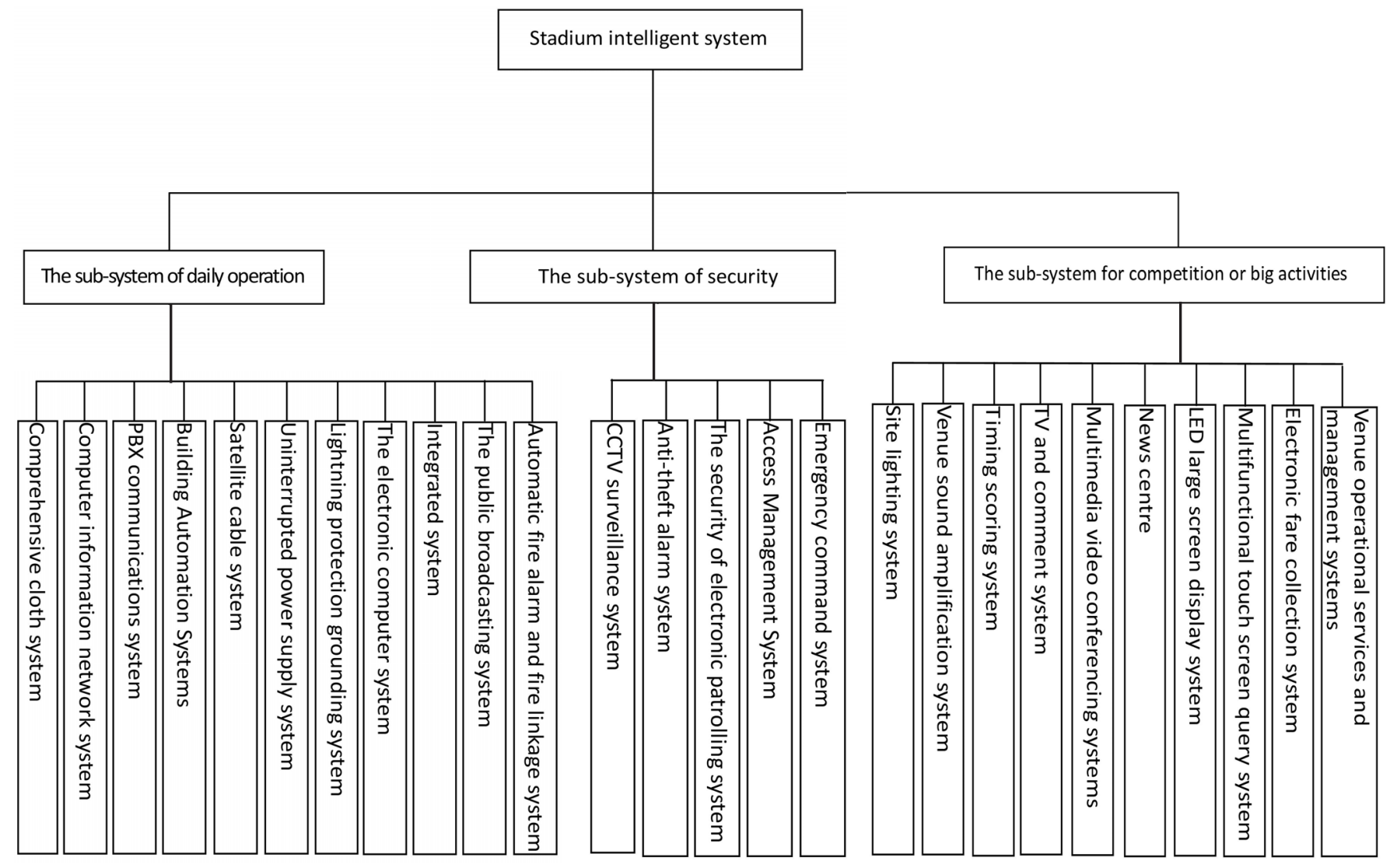

Figure 1. The figure of stadium intelligent system

Currently, the energy-saving idea, which is one of the goals in intelligent construction, is a large concept system and is closely related with the preliminary design \& simulation, the realization of control function and the later management. The energysaving can really realize only by viewing the problem of intelligent construction from a large concept system. However, the energy-saving idea has already deeply rooted in people's heart without a clear definition on the large system. The specific implementation has not been taken into systematic consideration, but start only from a limited perspective with a view to realizing energy-saving by utilizing automatic system under simplistic thought. Moreover, when considering the design of system, saving electricity, such as the application of ice storage system on air-conditioning equipment, can also be adopted etc. The construction of intelligent building control system in China is on a certain level, however, in contrast with developed countries, we still fall behind. In fact, the connection of automatic system, the performance of preliminary function, controllability optimization, which aim at making system operation reach design goal and develop the domestic building control system with its own characteristics, is the trilogy of BAS system. Most of the control systems that we used are foreign brands. It is a long journey for the development of building control system.

\subsection{Development Situation of Domestic Stadiums Intelligent System 4.2.1 The Climax of Stadiums Intelligent Systems Construction}

With the ceaseless improvement of living standards and material level, higher demand in life is needed, including the sports \& leisure activities. In our sports venues, per capita rate is far below the level of developed countries. Moreover, the existing stadiums are very dilapidated due to the long time span, sometimes; the existing stadiums have been closed, being unable to satisfy the need for physical exercise due to the poor exploitation. The successful holding of The Olympic Games in 2008 in Beijing provided a good opportunity for the emergence of stadium. The new 11 competition venues, 11 stadiums by alteration and 9 temporary stadiums are to be built. The stadium building also has peaked in many cities and provinces in China under such a circumstance. The National Sports Center in Nanjing is built for the 10th National Games. Jinan Olympic Sports Center, where the National Eleventh sports meeting will be held, has also been under construction. Zhuzhou City Sports Center, is now fully completed where the 10th National Games were held in September. Suffice to say, the stadium construction has peeked in China. 
In the previous years, the intelligent system was rarely taken into consideration. However, with the development of intelligent construction and the deeper understanding to intelligent system in recent years, the intelligent system plays a more and more important role in the competition and becomes an important part in the stadium construction. Suffice to say it is the extension and expansion during the whole process. The extent of intelligent system construction usually determines the level of the stadium. Stadium intelligent system has become an indispensible component in the stadium construction.

\subsubsection{The Project of Stadium Intelligent System is to be improved}

The rate of penetration and application increases gradually and so does the experience of project design, planning and management. Project management model also transitions from the simple one-way contract to intelligent systems engineering contract. Nevertheless, the intelligent buildings in China are on the way of development: the low level of engineering construction, the unsatisfactory project quality, the incomplete intelligent systems, and the misfunctional operation. What is worse, some intelligent projects are unable to be handed in, thus causing investment waste. The actual implementation of the project construction management of intelligent systems in the construction of stadiums also exist many problems. In the planning and design stage, the specialized designers are rare due to the less demand in engineering design, thus making the demand for stadium blurry. In the early period, the comprehensive design and plan is rare: conversely, the adjustments and corrections are simultaneous with the construction. During the implementation phase of the project, the construction team of intelligent systems usually works late and the cooperation with civil engineering, air conditioning, and lighting is rather difficult. Intelligent systems usually cannot integrate well with the stadium construction, usually separately. In the final stage, the lack of criteria on intelligent system has made the inspection work blocked, without reference. And the quality problem appears naturally. In routine maintenance, due to the limited level of property management companies, coupled with the incomplete intelligent system design, some intelligent system has become a decoration, being unable to function well.

\subsubsection{The Lack of Experience for Stadium Intelligent Construction}

Since the experience for stadium intelligent construction is limited, we have no mature stadium intelligent construction criteria to be referred to. By the end of 2002, in the field of national standards, the Chinese national standard directory, sports standards only account for less than 1\%. (2) Since the late development of sports equipment standardization, the specialized sports equipment criteria is absent. So the need of stipulating scientific, regular and advanced stadium is urgent. Country General Administration of Sports facilities and standard office, acting as standard in sports facility industry and implement unit, is planning to start building intelligent systems standard formulation, expecting to act as guidance and reference for management, planning, design and construction of stadium intelligent systems.

\subsubsection{Daily Stadiums Intelligent Management System is Limited}

The main function of stadium is to carry out sports competition. However, the time is less. So the problem of how to better utilize stadium to make it play a greater role in daily life and to reach better operational result is the priority for the developers and designers. In particular, the intelligent system design must take the dual functions (competition and daily use) into consideration.

Despite the completion of intelligent system in many stadiums, the management of property companies is far from the criteria due to the poor trained technicians and fast personnel changes etc. So the system put into practice is in high failure rate which is caused by improper use. Even some high-tech systems (such as building self-control system) are paralyzed and cannot be used for long time.

\section{The Characteristics of Stadium Intelligent System}

\subsection{Highly Specialized Engineering Technology}

Due to the specific nature of sport stadiums, in contrast with other civil intelligent systems, it is highly professional. Since the whole construction serves for competition and training, then the intelligence design should also revolves closely around the all kinds of demands. Then the designers are required to familiarize with the traits \& regulations of competition and the various demands of athletes, coaches, referees, news reporters, spectators and distinguished guest etc. These professional requirements in other intelligent building are rare, not so stringent.

\subsection{The Differences of Emphasis Compared with other Common Intelligent Construction}

In the intelligent system design of ordinary intelligent mansion, building automation system occupies a very prominent position, which is the key in realizing building comfort and energy efficiency. And in the stadium intelligent system design, computer networks, integrated.

$94 \quad$ Journal of Intelligent Computing Volume 10 Number 3 September 2019


Wiring, site lighting control, big venue screen, grades system which is directly related with sports competition, television systems, athlete registration system, the news release system etc become more important. This is the different focus on construction. The ordinary intelligent mansion emphasizes the inner building equipment management; however, stadium emphasizes the system related with competition.

The stadium intelligent system should stick to the principle of importance protrusion, conciseness, reality and people-orientation, avoiding the unnecessary technology accumulation outside the practical needs.

\subsection{The Construction goes with Multiple Majors and Complex Technologies}

Stadiums intelligent system generally consists of more than two dozen subsystems. Since stadiums are generally in the form of building construction, including the stadium, stadium, and swimming pool composition; each intelligent system of each venue is relatively separate, but are also interdependent and information-sharing with other buildings. Design should consist with the specific characteristics and usage. Different stadiums are also disparate in design and equipment. The integral design, systematic coloration and the interrelation also should be taken into consideration in order to guarantee the design is nor out of the date. Furthermore, the intelligent system, as the integral part of the building, also should coordinate with other relevant majors, such as mechanical and electrical equipment professional, civil engineering professional, renovation professional, craft professional sports, etc. Intelligent construction, the component of building, not only cooperates with other majors but also calls for the coordination of other majors. Since the demand for cooperation is high, it is a must to have good communication and coordination with each major.

The stadium intelligent system design coves various areas with Technical complexity and High-tech, such as computer professional, professional control, electric Sub-professional, professional acoustics, optics professionals, systems integration expertise, network information professionals etc. This is also the difficulty and peculiarity of stadiums intelligent construction, calling for the joint effort of different majors, help from each other and learning from others. So the challenge of design is imaginable.

\subsection{Complex game Integrated Pipeline}

The symbol of stadium is the sports supporting system, including timing and scoring system, TV Broadcast systems, personnel registration system card system, query results system, news release system etc. All kinds of reserved pipeline demanded by these systems should be given sufficient reserve space in the preliminary design in order to meet the demands of wirings supported by technology in various sports meeting.

\section{The Significance of Stadiums Intelligent Systems Research}

With the arrival of the Olympic project construction boom, China's sports venue construction has entered a new and unprecedented stage. Currently Beijing National Stadium (Bird's Nest) has begun to take shape, many domestic provinces and cities have built stadium one after another. Moreover, Shandong, which won the right to host the 2009 Eleventh National Games, has already devoted in Jinan Olympic construction. Design and implementation of intelligent systems is also an important component in stadium construction which can ensure the smooth proceeding of sports, provide comfortable and safe environment for people and improve the management level of property personnel.

Nowadays, such a huge market is both opportunity and challenge for each intelligent system integrators. The intelligent system design, planning, research for China is on the initial stage and many problems are to be dealt with in the process. In this thesis, we have set Zhuzhou intelligent system for example. Through practical summary about the existence of problems concerning intelligent system plan, design and project management etc, we have found out the resolutions and summarized relevant experience, hoping to be beneficial to the later stadium intelligent system and to provide reference for the criteria stipulated by government.

\section{Stadiums Intelligent System}

\subsection{Intelligent Power Distribution System}

Currently, stadiums have assumed various kinds of sports competition and performances and the extent of openness is on the rise. Meanwhile, the demand for stadium is becoming higher. Therefore, for the intelligent stadium construction, electrical distribution system usually applies intelligent design to improve the reliability of electrical distribution system. Accumulate the data in each system by light of sensor technology, and then transfer data to computer and tackle comes last. Calculation results 
can be visually displayed on the screen; meanwhile, power distribution system operation can be manipulated. Since the computer can be programmed, it is valid to realize automation and enhance working efficiency.

\subsection{Intelligent Lighting System}

Lighting System is critical for competition; moreover, light Illumination mode should also change accordingly in different cases. And an intelligent system is needed. At present, intelligent lighting system can design hierarchically to realize different functions through the communication network platform. Then control the lights and detect the lamp use automatically by light of compute and the malfunctions can be found and excluded timely, thus ensuring the normal function. In addition, you also need to consider emergency lighting design to prevent accidents from happening.

\subsection{Intelligent Security Monitoring System}

When holding competition or activities in stadium, for the venue managers, top priority is to ensure the safety of all the people entering the stadium. Therefore, there is a need to control the site during competition or activities, including the scope of venues and venues around. The surroundings around the venue mainly apply closed-circuit TV monitoring system, and exit and entrance of venue is camera in order to confirm the emergency timely. Once unforeseen circumstances happened, security personnel can arrive at the site immediately, thus enhancing the ability of tackling emergency. In addition, the door in the internal access is installed with FI detectors in order to prevent the illegal entrance.

\subsection{Smart Display System}

When holding sports competition, the real-time situation or game screen should be presented to the spectators directly in order to be convenient to watch the game. In the intelligent stadium, every part of the game is set with cameras. Then, transmit the screen to L E D display on top of the stadium via network platform. The display screen is able to present the competition process from various perspectives. Then process the data by light of integrated circuits, and spectators can watch the highlights of the replay camera.

\subsection{Cabling System}

In the process of stadium intelligent system construction, cabling is an effective platform for information and data transfer. In order to save costs and facilitate management, cabling must be designed according to stadium function and plan. Try to choose a more optimal solution; meanwhile, future development plan of network equipment and the reservation for power should also be taken into consideration. The system uses a star structure and is designed based on the standards of non-shielded Category 6 which can meet the use of fast Ethernet, Gigabit Gigabit Ethernet and other network.

\section{References}

[1] General Administration of Sports Group Company. Implementation planning of the second phase implementation program of Outline of Popular Fitness Program's Phase II ( 2006 - 2010 ) [EB/OL]. http://www.sport.gov.en/n16/n33193/n33208/rd3418/ n33598/1441 84.html, 2006-03-06.

[2] General Administration of Sports Group Company. Ideas and Key Points of Popular Sports Work in 2009[EB/OL]. http:// www.sport. gov.cn/n16/rd3193/n33208/n33418/n33598/1013911.html, 2008. 12-25.

[3] Wenjie, Wan. (2006). Research on the Effects of Community informatization on Community Communication Satisfaction. Zhejiang: Zhejiang University, 4.

[4] Xiaomin, Zhang. (2003). Study on Issues Related to Community Information Service System, Intelligence Science, (April).

[5] Kaizhen, Wang. (2004). Social Transformation and the Development of Chinese City Community Sports. Doctorate Paper (graduate) in Beijing Sport University, (April). 